Portland State University

PDXScholar

\title{
Academic Library Instruction, Evidence-Based Practice, and Social Workers: An Exploratory Survey
}

Kimberly D. Pendell

Portland State University, kpendell@pdx.edu

Ericka Kimball

Portland State University, ekimball@pdx.edu

Follow this and additional works at: https://pdxscholar.library.pdx.edu/ulib_fac

Part of the Information Literacy Commons

Let us know how access to this document benefits you.

\section{Citation Details}

Pendell, Kimberly D. and Kimball, Ericka, "Academic Library Instruction, Evidence-Based Practice, and Social Workers: An Exploratory Survey" (2020). Library Faculty Publications and Presentations. 320. https://pdxscholar.library.pdx.edu/ulib_fac/320

This Post-Print is brought to you for free and open access. It has been accepted for inclusion in Library Faculty Publications and Presentations by an authorized administrator of PDXScholar. Please contact us if we can make this document more accessible: pdxscholar@pdx.edu. 
Academic library instruction, evidence-based practice, and social workers: An exploratory survey

Kimberly Pendell (Corresponding author)

Social Work and Social Sciences Librarian, Associate Professor

University Library, Portland State University

1875 SW Park Avenue

Portland, OR 97201

kpendell@pdx.edu

ORCID: 0000-0003-3149-1271

Ericka Kimball

Assistant Professor

School of Social Work, Portland State University

1800 SW 6th Ave., Ste 600

Portland, OR 97201

ekimball@pdx.edu

ORCID: 0000-0002-8938-6557 


\begin{abstract}
When social work students graduate and move into their professional practice, they also move into a vastly different information landscape than that of the academic environment. In order to better understand the use of evidence-based practice (EBP) and information sources in practice, the authors performed a national survey of social workers. This survey provides a snapshot of how frequently social workers employ EBP, their use of research articles and other information resources, and their prior library instruction. The researchers make recommendations for increased consideration of the practice environment in library instruction, open access advocacy, and outreach to the field.
\end{abstract}

\title{
Keywords
}

Social work, library instruction, research dissemination, professional practice

\section{Word Count}

5267 (plus tables and figures)

\section{Funding}

This study is not grant funded.

\section{Disclosure Statement}

The authors confirm there are no conflicts of interest associated with this study. 


\section{Introduction}

Library instruction is common for social work students to experience during their academic program. The type and extent of instruction can vary, but generally it takes the form of an orientation to library services and resources, course-integrated sessions, or a combination of both. This instruction is likely to focus on helping students succeed in their courses and program --an important priority. However, when social work students graduate and move into their professional practice, they also move into an information landscape vastly different from the academic environment. This leaves social work librarians with a conundrum. What does the practice information landscape look like? Is the instruction provided useful in this other context? How can instruction both satisfy their immediate course assignment needs and their future practice needs?

Parallel to the efforts of social work librarians, social work educators are teaching students practice approaches such as Evidence-based Practice (EBP) and research-informed practice. EBP is a common, and sometimes mandated, approach in social work practice that explicitly includes identifying and evaluating research appropriate to the practice need. For a further explanation of EBP in social work, see the National Association of Social Workers (n.d.). EBP is not without criticism, but it is common practice. Also, finding, analyzing, and applying research evidence are key competencies of the required research methods course in a social work program, whether strictly defined as EBP or not. The Council of Social Work Education, the accrediting body of social work programs, requires social workers "engage in practice-informed research and research-informed practice," specifying that they understand "processes for translating research findings into effective practice" $(2015,8)$. EBP and research-informed practice require access to research literature at a minimum, but lack of access and a myriad of other barriers to implementation of these approaches have been identified (Osterling and Austin 
2008). Social work educators, like librarians, are also left to wonder how to both teach the standard, rather idealized, curriculum, and also account for the resource poor workplaces students will likely experience in the future.

These shared concerns brought together the authors, a social work librarian and a social work educator, who collaborated on this survey-based study in order to explore the information landscape of practicing social workers, particularly in relationship to EBP and library instruction. While brief and largely multiple choice, the survey data provide a window into social work practice that can inform curriculum, outreach efforts, and be expanded upon in future studies.

\section{Literature Review}

The literature that informed this study resides in two primary areas: library instruction and information literacy for social work students in the library literature and use of research related to EBP in social work literature. Only rarely do these two areas overlap; librarians understandably focus almost exclusively on instruction while in the academic environment, social work researchers focus on implementation of EBP in the workplace. This separation between academic environment and practice environment literatures echoes the larger "two communities theory" discussed by Gray et al. (2015) in their article "Connecting research to action: perspectives on research utilisation." The theory of two communities, one of research and academia, the other of practice and organizational culture, each with their own context and priorities, is useful for understanding the unfortunate disconnect between research and research utilization in the field. Interactions with other librarians, such as hospital or public librarians, also appear to be absent in the literature. Overall, the role of librarians, whether academic, hospital, or public, in this larger dynamic of research versus practice remains largely unexamined in the field of social work, even though lack of access to research articles and training to 
efficiently search databases are cited as barriers for practitioners (Teater 2017; Gray et al 2013; Bledsoe-Mansori et al 2013).

Literature on library instruction for students in social work programs understandably centers on information literacy, teaching methods, and assessment in the classroom or program. For example, Gall (2014) examined in-person versus asynchronous library orientations for social work students. Brustman and Bernnard (2008) discussed the curriculum and assessment of a set of required workshops for social work students. Bellard's (2005) case study also examined a required information literacy workshop for students. Bausman and Laleman Ward (2015) investigated social work students' engagement with library services over multiple years, finding that independent interactions with library services and resources increased along with changes in library instructional approaches. One study that explicitly merged information literacy and EBP instruction efforts was Bingham, Wirjapranata, and Chinnery (2016). This study found that a primary challenge was that students often lacked the foundational information literacy skills needed to effectively fulfill the requirements of EBP, such as evaluating information sources.

Eyre had the rare opportunity to explore a librarian's role in the practice environment as an embedded librarian in an online space to support social work students during their fieldwork. In his thought-provoking article, the tension between the aforementioned "two communities" of academia and practice are clear. Eyre $(2012,345)$ found that in the workplace there "is the strong distinction made amongst the social work community of a dichotomy between theory (university) and practice (the workplace), with the balance of importance weighing heavily in favour of the latter." The challenge of librarians then is to consider how their focus on "codified" types of information, such as research articles, is misaligned with the realities of workplace information. Considering the fundamental differences, Eyre $(2012,347)$ proposes that librarians 
focus more on the "critical engagement" that is valued in the workplace; for example, "the critical evaluation of sources and their relevant application to the solving of problems..."

A more recent article by Magliaro and Munro (2018) provides a thorough and useful literature review on the subject of library instruction for social work students, with summaries of eight articles, including some cited here. Based on their analysis of the literature, Magliaro and Munro $(2018,7)$ conclude that the "need for integrating information literacy into social work curricula and for collaboration between faculty and librarians, librarians and students, and librarians and social work practitioners so that social workers can be effective researchers and practitioners." This call for increased collaboration and information literacy integration is a common refrain in the library literature. However, if progress were to be made on these points, assessment beyond graduation would probably still be problematic, just as it is for social work educators. "While more than half of the respondents [social work librarians] state they perceive that their students graduate with the IL skills necessary for professional practice, very few have the opportunity to employ a reliable method by which to evaluate that this is so" (Bausman and Ward 2016, 119).

In order to better understand the practice paradigm in which the conceptual knowledge and research skills gained via library instruction are represented, the authors also examined the EBP implementation related literature. The literature on this topic is extensive, and there are many identified barriers to the implementation of EBP in social work. Osterling and Austin (2008) synthesized a number of studies to create a list of barriers that span the conventions of research and scholarly communication, organizational culture, and individual training.

The barrier that librarians are likely most familiar with, and could impact most immediately via instruction and advocacy, is that of access to research. The question of access in 
the field post-graduation is a common one for social work librarians. Focus group participants affirmed this in Jivanjee et al. (2016) when they expressed their concern about the lack of access to research literature after leaving the academic environment, knowing via their field practice that access will be greatly reduced. This reduced access also results in reduced implementation of EBP. In their review of multiple studies, Gray, Joy, Plath, and Webb $(2013,163)$ conclude that "the need to invest resources in staffed library facilities and information technology to access web-based databases was identified as a requirement if there were to be a movement from EBP as an aspiration to a reality." Many social work agencies would find such expensive investments very challenging. Social workers who participated in a multipart EBP training program also encouraged investment in training and access to research: "Participants noted that demonstrations and search tips, including clarification on the use of Boolean terms, were helpful" (Bledsoe-Mansori et al 2013, 81). Participants also suggested "that universities and/or professional associations, such as the National Association of Social Workers, might partner with agencies to provide practitioners with access to fee-based search engines and full text journal articles" (Bledsoe-Mansori et al 2013, 81).

Knight (2013) found that social workers were not reading peer reviewed literature available to them. But it is critical to note that participants' access was quite limited in Knight's study. Almost $75 \%$ of participants access to research articles was primarily only via one journal, Social Work, the research journal of NASW. A similar number of participants indicated their agency did not subscribe to any peer-reviewed journals. Therefore, these participants lacked any breadth of access to potentially useful literature. Lack of research relevance from such a narrow resource as one journal title may have been contributing factors to the practitioners' low use of articles. 
Free access to research articles can impact their use in the practice environment. Hardisty and Haaga $(2008,833)$ explored mental health clinicians' behavior when asked to access and read an article: "Free access citations were significantly more likely to report reading the article than were those in the other three conditions. Reading rates in the free access condition were roughly 2.4 times the average of those in the linked and normal citation conditions." Many studies recognize access as a barrier, but the traditional paywalled article model appears to be viewed as standard by EBP implementation researchers. Open access publishing or the use of disciplinary or institutional repositories are almost never mentioned in the context of EBP or other literature regarding research dissemination, even though both open access scholarly publishing and repositories have been firmly established for at least a decade.

There were two exceptions to the neglect of open access in the social work literature: Bowen, Mattaini, and De Groote (2013) and Pendell (2018). Bowen, Mattaini, and De Groote $(2013,38)$ discussed the problem of subscription cost for social workers and the benefits of open access publications. "Subscription rates present significant barriers...for individuals being asked to pay an average of $\$ 30$ for a single article download or $\$ 121$ for an annual online subscription." These rates have risen since the writing of their study; single article download rates of $\$ 35-\$ 40$ are common to see from publishers in 2019. Pendell (2018) examined the disconnect between explicit and implicit expectations that practice be based on research and the lack of access to that research. By performing a citation analysis, Pendell found the availability to primary research articles from top twenty-five social work-related journals at around 50\%. This amount drops significantly if articles posted in violation of copyright on platforms and therefore subject to take down notices are subtracted. Pendell ends with a call for researchers to publish with open access journals and practice self-archiving in institutional or disciplinary repositories. 
The literature outlines a complex situation for librarians, educators, researchers, and practitioners. Librarians work to integrate information literacy with social work curricula, but often face constraints related to effective collaboration with social work educators, meaningful assessment, and disconnect from the practice information. Educators have to contend with social workers' ability to implement EBP or research-informed practice, which is heavily impacted by their lack of access to research and other organizational/workplace limitations. Researchers producing studies with the intent to impact practice are not necessarily reaching the desired audience, especially if the studies are only available to those few with memberships or subscriptions. In order to have a snapshot of social workers' engagement with EBP and information sources, this study asked them to rate frequencies of EBP use, rank their information sources, and describe any previous library instruction. The results are informative for both librarians and social work educators in building awareness of the practice environment in the academic curriculum.

\section{Methods}

The authors used a cross-sectional survey of social workers in the United States to collect data regarding EBP, access and use of information to inform social work practice, and library instruction during their social work academic program. This study was approved by the authors' Institutional Review Board. The 25-question survey was based on a review of literature from the fields of social work and library science. Participants were asked basic demographic information, the importance and frequency of EBP use; barriers to using EBP; access and use of information to inform practice (e.g. peer reviewed articles, continuing education trainings, and social work supervision); and library instruction. The survey was voluntary, and participants were free to skip any questions they did not want to answer. 
Participants were recruited through Twitter, Facebook professional groups, LinkedIn professional groups, and a recruitment letter to a field instructor email list. Participants selfidentified as social work practitioners. Prior to responding to the survey, participants provided their informed consent. Gift card incentives were randomly awarded to four participants who selected to provide their contact information for that purpose; contact information was submitted via a form separate from the survey that was available at the completion of the survey. The survey was open for data collection from April to August 2019, with a total of 123 participants who completed the survey.

Descriptive statistics were used to explore social work practitioners' access and use to research. As participants were not required to answer individual survey questions, not all questions generated the same number of responses as the number of participants. Univariate analysis was used to explore the use of EBP, sources of information to inform social work practice, access to peer reviewed materials, and library instruction. Bivariate analysis was conducted to examine any group difference between participants in an academic role and those without connections to academia. No significant differences were found between these groups. For the survey's two open text response questions, the authors separately grouped the responses according to similarity and then validated the groupings together. These response groups are presented below as themes.

\section{Results}

As mentioned, participants were not required to answer every survey question, so the number of total responses below will vary and not equal the total number of participants. Also, some questions allowed for multiple responses, and therefore presented as frequency counts. 


\section{Demographics}

Survey participants $(n=123)$ represented a diversity of ages, but predominantly fell into the range of 35-44 years old (37\%). Other participant ages were: $18-24,3 \% ; 25-34,20 \% ; 45-54$, $21 \% ; 55-64,16 \% ; 65+, 4 \%$. A large majority of respondents, $84 \%$, had MSW degrees, $10 \%$ had a BSW, 5\% had doctorate (PhD or DSW). Nearly 90\% of respondents were employed full-time with the remaining reporting part-time employment. The survey participants represented a healthy geographic distribution; the survey reached twenty-one states, primarily on the East and West coasts, and the Midwest.

In regard to their practice area, largest clusters of participants work in healthcare and community mental health (see Table 1). It is likely that these clusters are reflective of the recruitment methods used and consequent convenience sample. Our recruitment methods also resulted in a very high number of participants, $75 \%$, that serve in an academic role (i.e. field instructor or field supervisor) for a CSWE accredited social work program.

Table 1. Practice area of survey participants

\begin{tabular}{|l|r|r|}
\hline Practice Area & N & \multicolumn{1}{l|}{$\%$} \\
\hline Healthcare & 30 & $25 \%$ \\
\hline Community based mental health & 24 & $20 \%$ \\
\hline Education/school based social services & 18 & $15 \%$ \\
\hline Private practice & 12 & $10 \%$ \\
\hline Community based social services & 9 & $8 \%$ \\
\hline Program Management & 6 & $5 \%$ \\
\hline Other & 5 & $4 \%$ \\
\hline State based social services & 4 & $3 \%$ \\
\hline Policy & 3 & $3 \%$ \\
\hline Program Development & 3 & $3 \%$ \\
\hline Court based social services & 2 & $2 \%$ \\
\hline Community Organizing & 1 & $1 \%$ \\
\hline Program Evaluation & 1 & $1 \%$ \\
\hline
\end{tabular}




\section{Evidence-based practice}

Of the 123 respondents, $85 \%$ reported receiving training in EBP or research-informed practices. Approximately, $85 \%$ rated EBP or research-informed practice as extremely or very important to social work practice. When asked how often they implement EBP, $14 \%$ said always and another $68 \%$ said most of the time.

The survey asked participants to indicate the three largest barriers they experience in implementing EBP. Lack of time and lack of research on relevant issues and/or populations were the two most frequently indicated barriers, followed by organizational culture and conflicting policies and procedures (see Table 2).

Table 2. Barriers to implementing EBP (multiple selections allowed)

\begin{tabular}{|l|l|}
\hline Barrier & $\begin{array}{l}\text { N times } \\
\text { selected }\end{array}$ \\
\hline Time & 68 \\
\hline Lack of research on relevant issues and/or populations & 67 \\
\hline Organizational culture & 53 \\
\hline Conflicting policies and procedures & 44 \\
\hline Cost & 9 \\
\hline Lack of training & 9 \\
\hline Other & 7 \\
\hline Other (no text response) & 2 \\
\hline
\end{tabular}

\section{Sources of information}

Participants were asked to rank the importance of nine different information sources for keeping current in the profession (1-5, 1 being most important). Table 3 displays the frequency count of the sources ranked as first and second most important. Peer reviewed articles were the second most important source, ranked both first and second, with guidelines/best practices documents third most important. 
Table 3. Rank of information source for keeping current (frequency count)

\begin{tabular}{|l|r|l|r|}
\hline Ranked 1st & $\begin{array}{l}\text { N of times } \\
\text { selected }\end{array}$ & 27 & $\begin{array}{l}\text { Ranked 2nd } \\
\text { Nof times } \\
\text { selected }\end{array}$ \\
\hline Coworkers & 25 & $\begin{array}{l}\text { Peer reviewed/scholarly/research } \\
\text { articles }\end{array}$ & 22 \\
\hline $\begin{array}{l}\text { Peer } \\
\text { reviewed/scholarly/research } \\
\text { articles }\end{array}$ & 25 & $\begin{array}{l}\text { Guidelines/best practices } \\
\text { documents and resources }\end{array}$ & 20 \\
\hline $\begin{array}{l}\text { Guidelines/best practices } \\
\text { documents and resources }\end{array}$ & 20 & Coworkers & 14 \\
\hline $\begin{array}{l}\text { Professional organizations } \\
\text { (e.g. NASW, AOSW, etc) }\end{array}$ & 9 & $\begin{array}{l}\text { Advocacy group or similar } \\
\text { reports }\end{array}$ & 11 \\
\hline $\begin{array}{l}\text { Advocacy group or similar } \\
\text { reports }\end{array}$ & 4 & Agency/organizational reports & 10 \\
\hline $\begin{array}{l}\text { Agency/organizational } \\
\text { reports }\end{array}$ & 3 & Professional agency websites & 10 \\
\hline Other & 2 & Social media & 2 \\
\hline Professional agency websites & 0 & Other & 1 \\
\hline Social media & & \\
\hline
\end{tabular}

Survey participants were additionally asked how they access information to inform their practice generally and regarding specific practice issues (see Figures 1 and 2). Results show heavy reliance on continuing education events, professional conferences, and peer reviewed articles as locations of information for both. Peer reviewed articles were accessed only slightly more often for specific practice issues than professional conferences. Supervision was the fourth most frequently selected source of general and specific information. Supervision is consulting with a seasoned practitioner on particular cases, ethics, and educational activities, required as part of seeking an independent license to practice, and also commonly used after licensure. 
Figure 1. How do you access information to inform your practice generally?

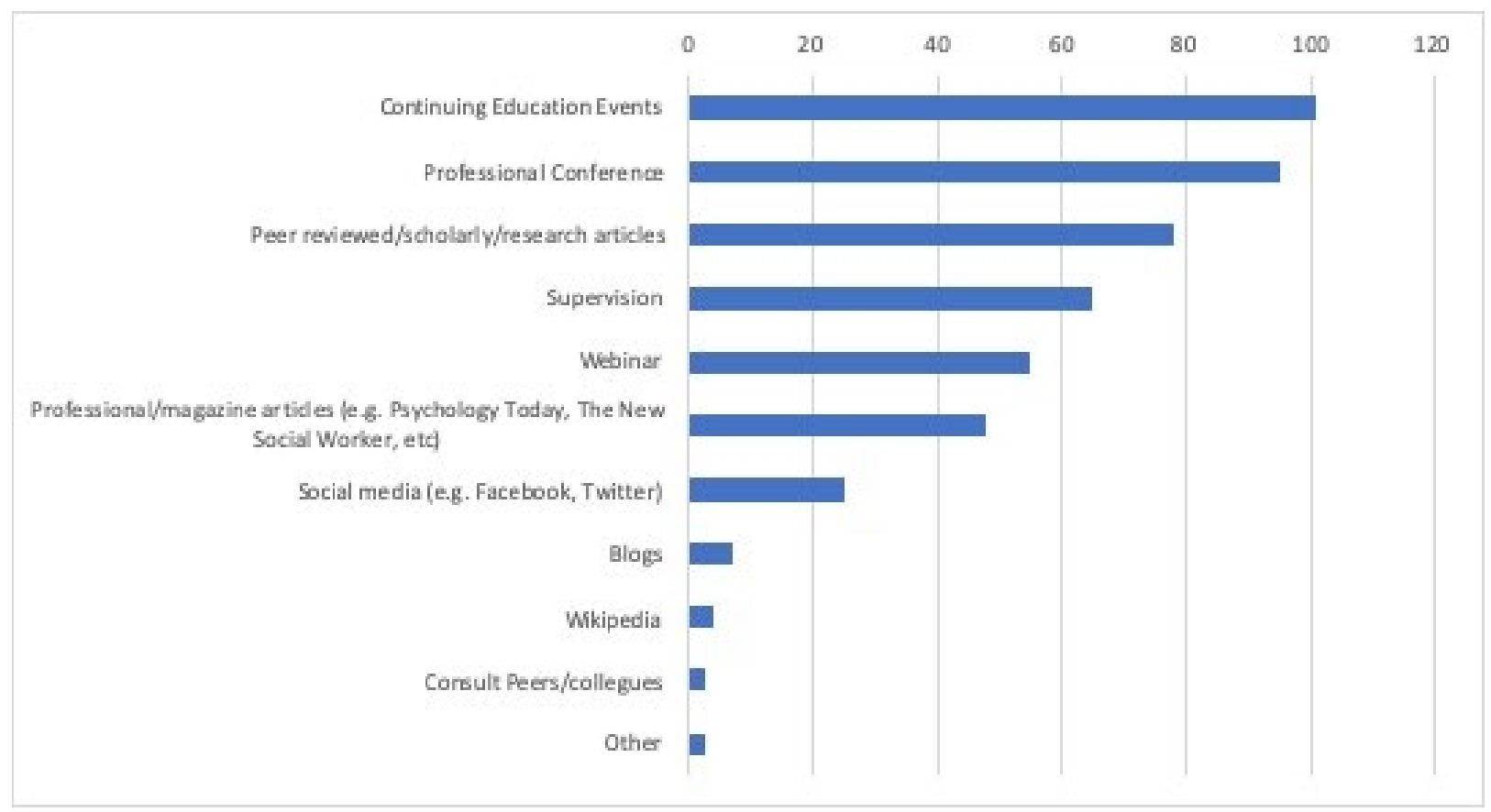

Figure 2. How do you access information on a specific practice issue?

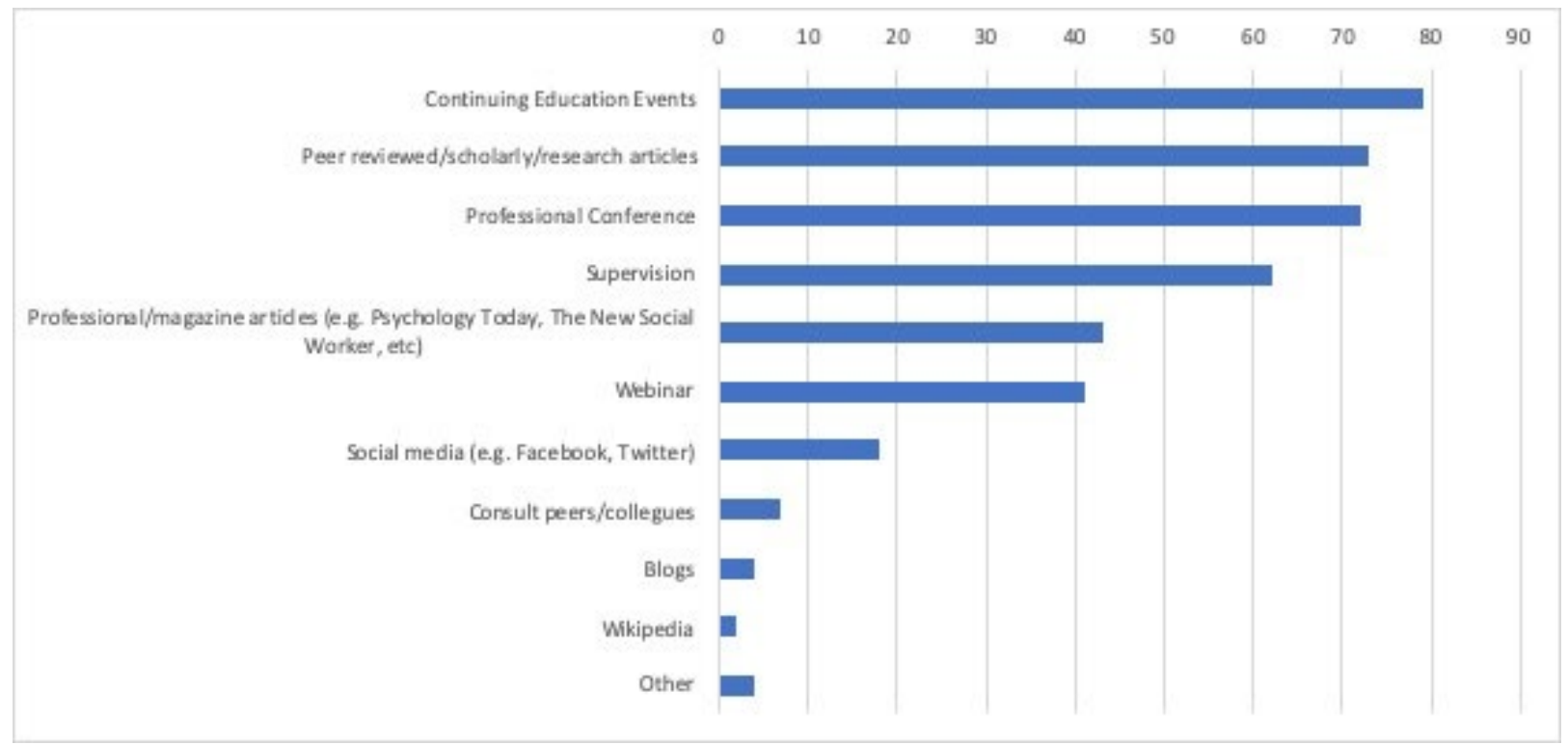

Access to peer-reviewed articles

Almost $60 \%$ of the 123 respondents were able to access peer reviewed articles. Of those who had access, $71 \%$ have access through personal membership or agency subscription. 
Participants who indicated that they serve in an academic role such as field instructor $(\mathrm{n}=92)$ were additionally asked if they are able to access peer reviewed articles via this role. About 52\% indicated that they did, while of the remaining respondents $32 \%$ didn't know whether they did or not, and $14 \%$ did not have access via this role.

When asked how often they access peer reviewed materials, of the 121 respondents to this question $12 \%$ reported always, $75 \%$ reported sometimes, and $12 \%$ reported never. The results were similar when asked how often they referred to peer reviewed materials in the course of their work: $8 \%$ always, $79 \%$ sometimes, and $12 \%$ never. Of the 35 respondents who were unable to access peer reviewed articles, $91 \%$ identified cost as the primary barrier to access.

\section{Library instruction}

In response to the question "Did you receive instruction from a librarian during your social work education regarding searching, evaluating, or accessing information resources such as journal articles?," slightly over half of the respondents reported receiving instruction from the librarian on searching, evaluation, or accessing information resources such as journals. Thirty percent did not receive instruction while another $18 \%$ did not remember receiving instruction from a librarian. Participants who indicated they had received instruction were then asked to rate perceived usefulness of library instruction to their work today (see Table 4).

Table 4. Rate the usefulness of library instruction to your work today

\begin{tabular}{|l|l|l|}
\hline Rating & N & $\%$ \\
\hline Extremely useful & 11 & $21 \%$ \\
\hline Moderately useful & 29 & $50 \%$ \\
\hline Neither useful or useless & 14 & $23 \%$ \\
\hline Moderately useless & 5 & $6 \%$ \\
\hline
\end{tabular}




\begin{tabular}{|l|l|l|}
\hline Extremely useless & 0 & $0 \%$ \\
\hline Total & 59 & $100 \%$ \\
\hline
\end{tabular}

Participants also answered two open text questions regarding library instruction: "what was the most useful thing you learned from the library instruction? and "what was missing from, or not helpful about, the library instruction? The responses to each of these two questions were grouped by theme (see Tables 5 and 6). Based on responses, it can be surmised that many of the participants have been out of the academic environment for a significant period of time due to comments about using the card catalog and significant technology changes since they had instruction.

Table 5. Responses to "What was the most useful thing you learned from library instruction?"

\begin{tabular}{|l|l|}
\hline Theme & N \\
\hline Searching for resources & 16 \\
\hline Accessing resources & 12 \\
\hline System or website navigation & 8 \\
\hline Evaluating resources & 5 \\
\hline Asking for help & 3 \\
\hline Other & 4 \\
\hline
\end{tabular}

Table 6. Responses to "What was missing from, or not helpful about, library instruction?"

\begin{tabular}{|l|l|}
\hline Theme & $\mathrm{N}$ \\
\hline Nothing or does not remember & 17 \\
\hline Access to resources after graduation & 8 \\
\hline $\begin{array}{l}\text { Information missing from instruction or critique } \\
\text { of instruction }\end{array}$ & 5 \\
\hline
\end{tabular}




\begin{tabular}{|l|l|}
\hline $\begin{array}{l}\text { Technology or tools used too different than } \\
\text { those used presently }\end{array}$ & 5 \\
\hline Instruction not perceived as useful & 1 \\
\hline Other & 3 \\
\hline
\end{tabular}

In response to the first question, many participants gave short answers, and many started their response with the phrase "how to..."; for example, "How to navigate the library website," "How to search for social work resources," and "How to access peer reviewed articles." More participants responded to the first question than the second $(n=48 ; n=39)$, and the majority of responses for the latter were variations of "not applicable" or "I don't remember." Of the other responses to the second question, the most potentially useful for informing library instruction were those grouped as "information missing from instruction" and "access to resources after graduation." Participant comments on instruction included that they "wished there had been more" and they would have liked "more in-depth knowledge and hands on learning of the variety of search tools that are out there." Access related responses included: "how to find information when library resources are not available (i.e., no longer a student with journal database access)," "how to pay for access to these after school while paying back student loans and working in a profession that does not allow for much disposable income," and "other ways to access databases that are not housed by the library."

\section{Discussion}

Participants in this survey appeared to be quite engaged with EBP overall, citing it as utilized most of the time in their work and very important to their work. This result could be influenced by the number of participants working in healthcare. EBP emerged from medicine, and the approach is very common in healthcare settings. However, participants using EBP do 
experience barriers that others face. The barriers of time, organizational culture, and conflicting policies and procedures are inherently intertwined issues in the workplace. Another cited barrier to EBP is the lack of research on relevant issues and/or populations, another echo of the "two communities" disconnect between research and practice (Gray et al. 2015).

The survey results demonstrate frequent utilization of peer reviewed articles by social workers in multiple contexts: keeping current with the profession, informing their practice generally as well as specific practice issues, aligning with their frequent use of EBP which emphasizes the use of primary research literature. However, like the other challenges of implementing EBP, the access to research articles is complicated. Many participants identified as serving in an academic role, such as field instructor, but $32 \%$ did not know whether they had access to licensed content via this role or not. Schools of social work and their respective institutions define the affiliation privileges of individual practitioners serving in such a role differently. At the authors' institution, active field instructors have affiliated accounts that allow them access to full text journals. Both the survey results and anecdotal information from social work librarians indicate this is not the case at every institution. Some field instructors work with social work students in the field without the benefit of library access. That said, field instructors could be a neglected audience in terms of librarian outreach. Exploration of their access privileges in these roles, and promotion of what is available to them, could increase access to research in the field for these individuals.

For those who are unable to access peer reviewed articles at all, the strong majority of respondents cited cost as the primary barrier. This is unsurprising as subscription costs can be cumbersome for agencies and individuals, as discussed by (Bowen, Mattaini, and De Groote 2013). If the field of social work aims to successfully implement EBP or research-informed 
practice, it will need to reckon with current research dissemination practices that keep content behind paywalls. From the related field of clinical psychology, Hardisty and Haaga $(2008,835)$ found that "dissemination efforts that come with a price tag may prove less effective, even if they are promoted more heavily, than dissemination efforts that are free." Hardisty and Haaga encourage "...scholars wishing to maximize the diffusion of their research among the professional community should deposit eprints of their work in OA archives" $(2008,836)$. In this space, librarians as advocates of open access publishing and repositories could make a difference. Increasing awareness among social work faculty researchers regarding their options for sharing their research in disciplinary or institutional repositories would increase access for social workers in the field.

Participants responding to what was useful from library instruction most often stated searching for resources, accessing resources, and system/website navigation. All three of these activities are very intertwined in practice, incorporating where to search, how to search, and how to access full text. Considering the complexity of many library discovery systems, vendor databases, and full text access via link resolvers, students and future practitioners will continue to need guidance on these more mechanical skills. On the more conceptual side, evaluating the quality of information sources was mentioned by some participants as the most useful part of library instruction. A few participants wished there had been more library instruction available to them. As is common in library instruction, it is challenging to effectively teach mechanical skills, such as searching, and important concepts, such as quality and authority, in the short one-shot most librarians have with students. Integration and scaffolding of information literacy throughout the social work program curriculum would be the most effective, as others have argued (Magliaro and Munro 2018, Bingham, Wirjapranata and Chinnery 2016). 
Participants also expressed desire for guidance on how to access resources postgraduation. This raises an important question for social work librarians whether to focus exclusively on the licensed resources perhaps best for students' course assignments (e.g. PsycINFO) or be more explicitly inclusive of publicly available databases and search engines they will be able to use post-graduation, such as PubMed and Google Scholar. Simple full text access to a desired article is another problem in the practice environment identified by survey participants. Promotion of OA journals and repositories (e.g. PubMed Central, PsycArXiv) could also serve students, especially as they approach graduation.

One possible venue for collaboration between social work educators and librarians outside of the standard social work program curriculum is continuing education for practitioners. Continuing education ranked very high among participants as a space for keeping up with the profession and informing practice. Continuing education centered on effective searching and access to research in the practice environment could be valuable to many social workers, especially as some participants pointed out--the tools and platforms have changed quite a bit since they were in their academic program. Other educational possibilities for social workers are outreach and workshops on open access journals, institutional and disciplinary repositories, gray literature, and other publicly available sources of research-based content.

As Eyre $(2012,348)$ stated in his discussion on the disconnect between the academic and workplace environments for social work practitioners, "it is incumbent on academic librarians to recognise the limits of library-based information literacy teaching as it is currently conceived and to work in partnership with others in higher education and -- crucially-- beyond it to better reflect the information needs of graduates beyond a formal education setting." And, while Eyre might be correct that librarians need to think beyond the academic environment and work in partnership 
with social work educators, this is not a one-sided venture. The lack of discussion in the social work literature related to information literacy, library instruction, publicly available access to research, or calls to collaborate with librarians is noticeable and disappointing. Changing this might require multiple strategies, such as librarians collaborating with individual educators who might then act as champions for better integration of information literacy in the curriculum, and social work curriculum committees including the social work librarian in their discussions. Other possible strategies include larger organized efforts: promotion of the value of information literacy as foundational to effective research-informed practice within the Council for Social Work Education; open access advocacy within the Society for Social Work and Research as producers of research; and outreach to the National Association of Social Workers regarding open access as a means of improving evidence-informed practice, and the support of library instruction as continuing education.

Limitations of this study include a non-standardized instrument; a convenience sampling of participants; and recruitment via email groups and social media channels available to the researchers, such as a field instructor listserv. The use of a non-standardized instrument impacts the accuracy and consistency of the data collected since participants could have a different understanding of the questions from the authors' intent. Recruitment methods impacted the reach of the survey into particular practice areas, which might have influenced results. Many respondents reported their practice area as healthcare related which relies heavily on EBP, and healthcare settings are more likely to support the access and use of peer reviewed materials. Finally, the study focused exclusively on the experience of participants with academic library instruction during their social work program and did not account for other possible instructional interactions with public or hospital librarians. Further research needed in this area of inquiry 
include interviews of social workers to further explore information seeking behavior and their organizational/practice environments; a better understanding of how researchers view dissemination to the field; and further exploration of how library instruction might account for both program/course requirements and future professional constraints.

\section{Conclusion}

Librarians and educators necessarily focus on the program curriculum when working with social work students, and ideally that curriculum is designed to support future successful practice. However, the information landscape in the practice environment is substantially different than that of the academic environment and has multiple barriers that hinder social workers implementing EBP and accessing needed information. This study demonstrates the importance of EBP and access to research articles for social workers. In order to support the effectiveness of these key areas, the study results and literature review suggest that librarians and educators could work together to better integrate library instruction and information literacy skills across the social work curriculum; expand the availability of information through open access and other freely available means of research dissemination; and collaborate on outreach and continuing education opportunities. These suggestions might help bridge the gap between the two communities of research and practice. 


\section{References}

Bausman, Margaret, and Sarah Laleman Ward. 2015. Library awareness and use among graduate social work students: An assessment and action research project.” Behavioral \& Social Sciences Librarian 34 (1): 16-36. https://doi.org/10.1080/01639269.2015.1003498.

Bausman, Margaret, and Sarah Laleman Ward. 2016. The social work librarian and information literacy instruction: A report on a national survey in the United States. Behavioral \& Social Sciences Librarian 35 (3): 109-22. https://doi.org/10.1080/01639269.2016.1243439.

Bellard, Eloise M. 2005. Information literacy needs of nontraditional graduate students in social work." Research Strategies 20 (4): 494-505. https://doi.org/10.1016/j.resstr.2006.12.019.

Bingham, Tricia Jane, Josie Wirjapranata, and Shirley-Ann Chinnery. 2016. Merging information literacy and evidence-based practice for social work students." New Library World 117 (3/4): 201-13. https://doi.org/10.1108/NLW-09-2015-0067.

Bledsoe-Mansori, Sarah E., Jennifer I. Manuel, Jennifer L. Bellamy, Lin Fang, Erna Dinata, and Edward J. Mullen. 2013. "Implementing Evidence-Based Practice: Practitioner Assessment of an Agency-Based Training Program." Journal of Evidence-Based Social Work 10 (2): 73-90. https://doi.org/10.1080/15433714.2011.581545. 
Bowen, Elizabeth. A., Mark A. Mattaini, and Sandra L. De Groote. 2013. Open access for social work research and practice. Journal of the Society for Social Work and Research 4 (1): 31-46. https://doi.org/10.5243/jsswr.2013.3.

Brustman, Mary Jane, and Deborah Bernnard. 2008. Information literacy for social workers: University at Albany Libraries prepare MSW students for research and practice.” Communications in Information Literacy 1 (2): 89. https://doi.org/10.15760/comminfolit.2008.1.2.12.

Council on Social Work Education. 2015. 2015 Educational policy and accreditation standards for baccalaureate and master's social work programs. Council of Social Work Education, https://www.cswe.org/getattachment/Accreditation/Accreditation-Process/2015EPAS/2015EPAS_Web_FINAL.pdf.aspx

Eyre, Jason. 2012. Context and learning: The value and limits of library-based information literacy teaching." Health Information \& Libraries Journal 29 (4): 344-48. https://doi.org/10.1111/j.1471-1842.2012.00999.x.

Gall, Dan. 2014. Facing off: Comparing an in-person library orientation lecture with an asynchronous online library orientation." Journal of Library \& Information Services in Distance Learning 8 (3-4): 275-87. https://doi.org/10.1080/1533290X.2014.945873. 
Gray, Mel, Elyssa Joy, Debbie Plath, and Stephen A. Webb. 2013. Implementing evidence-based practice: A review of the empirical research literature." Research on Social Work Practice 23 (2): 157-66. https://doi.org/10.1177/1049731512467072.

Gray, Mel, Elaine Sharland, Milena Heinsch, and Leanne Schubert. 2015. Connecting research to action: Perspectives on research utilisation." British Journal of Social Work 45 (7): 1952 67. https://doi.org/10.1093/bjsw/bcu089.

Hardisty, David J., and David A. F. Haaga. 2008. Diffusion of treatment research: does open access matter? Journal of Clinical Psychology 64 (7): 821-39. https://doi.org/10.1002/jclp.20492.

Jivanjee, Pauline, Kimberly D. Pendell, Laura Nissen, and Charlotte Goodluck. 2016. Lifelong learning in social work: A qualitative exploration with practitioners, students, and field instructors." Advances in Social Work 16 (2): 260-275. https://doi.org/10.18060/18407.

Knight, Carolyn. 2013. Social workers' attitudes toward peer-reviewed literature: The evidence base. Journal of Teaching in Social Work 33 (2): 177-95. https://doi.org/10.1080/08841233.2013.773955.

Magliaro, Jelena, and Sharon Munro. 2018. A study of the information literacy needs of social work graduate students at a mid-sized Canadian university." International Journal of Librarianship 3 (2): 3-35. https://doi.org/10.23974/ijol.2018.vol3.2.79. 
National Association of Social Workers. n.d. Evidence-based practice. National Association of Social Workers, https://www.socialworkers.org/News/Research-Data/Social-WorkPolicy-Research/Evidence-Based-Practice.

Osterling, Kathy L., and Michael J. Austin. 2008. The dissemination and utilization of research for promoting evidence-based practice. Journal of Evidence-Based Social Work 5 (1-2): 295-319. https://doi.org/10.1300/J394v05n01_11.

Pendell, Kimberly. 2018. Behind the wall: An exploration of public access to research articles in social work journals. Advances in Social Work 18 (4): 1041-52. https://doi.org/10.18060/22180.

Teater, Barbra. 2017. "Social Work Research and Its Relevance to Practice: 'The Gap Between Research and Practice Continues to Be Wide."' Journal of Social Service Research 43 (5): 547-65. https://doi.org/10.1080/01488376.2017.1340393. 